\title{
Kajian Geo Homestay Kawasan Geopark Tambora
}

\author{
Zulharman $^{1}$, Ibnu Khaldun Sudirman ${ }^{2}$, Asriyadin ${ }^{3}$ \\ ${ }^{1}$ STKIP Taman Siswa Bima \\ ${ }^{1}$ zhul_one@yahoo.co.id
}

\begin{abstract}
ABSTRAK
Homestay adalah sebuah rumah tinggal yang berada di dekat kawasan wisata yang berfungsi untuk penginapan sementara bagi wisatawan untuk melihat dari dekat kehidupan sehari-hari masyarakat, melihat pemandangan, dan bahkan menjalani kehidupan seperti penduduk lokal. Tujuan dari penelitian adalah untuk mengetahui model pengelolaan homestay yang ada di kawasan geopark Tambora Kabupaten Bima dan Dompu, Provinsi NTB. Penelitian dilaksanakan di kawasan Geopark Tambora yang terdiri dari wilayah Kecamatan Pekat Kabupaten Dompu dan Kecamatan Tambora Kabupaten Bima. Adapun waktu penelitian dilakukan pada bulan Maret 2018 sampai Juni 2018. Penelitian ini dilakukan dengan pendekatan rasionalistik dengan analisa deskriptif kualitatif. Penelitian ini menggunakan metode survey dengan teknik pengumpulan data dengan cara wawancara snowball, observasi lapangan dan studi kepustakaan. Jenis data yang digunakan dalam penelitian ini adalah data primer dan data sekunder. Data primer berupa hasil observasi di lapangan, sedangkan data sekunder diperoleh berdasarkan studi kepustakaan yang meliputi jurnal, buku dan media internet. Analisis data dilakukan dengan analisis deskriptif kualitatif. Hasil penelitian menunjukan bahwa kawasan Geopark Tambora terdiri dari 10 geosite utama yang memiliki daya tarik wisata. Potensi wisata pada setiap geosite berbeda-beda sehingga memerlukan konsep geohomestay yang mencerminkan potensi pada setiap geosite. Terdapat 7 kawasan utama sebaran geo homestay yang akan dikelola berdasarkan criteria antara lan akes, jarak anatar geosite, pemukiman dan fasilitas penunjang geo homestay. Perancangan kawasan geo homestay harus memperhatikan unsur-unsur kandungan lokal seperti rumah-rumah penduduk serta budaya dan tradisi yang ada untuk diterapkan dalam tema geo homestay.
\end{abstract}

Kata kunci : Homestay, Geopark, Tambora

\section{PENDAHULUAN}

Indonesia sebagai negara megabiodiversity nomor dua di dunia setelah Brasil memiliki banyak kekayaan alam berupa flora, fauna maupun keindahan alam. Kondisi demikian menjadikan Indonesia sebagai daerah tujuan wisata potensial bagi para wisatawan yang merupakan petualang-petualang yang ingin menikmati keindahan alam Indonesia dan ingin mengetahui lebih banyak tentang keanekaragaman hayati Indonesia. Potensi ini harus dapat direspon dengan strategi pengembangan kawasan potensial sebagai daerah tujuan wisata yang dapat memberikan nilai ekonomi secara nasional maupun bagi masyarakat local dengan tetap memperhatikan keberlanjutan ekosistem yang ada (Fandeli, 2005:3).

Salah satu upaya potensial yang dapat dilakukan untuk melestarikan budaya dan alam dalam bingkai pariwisata adalah dengan membuat geopark. Konsep geopark ini berfungsi sebagai daerah tujuan wisata yang dapat mengakomodasi fenomena pariwisata yang berorientasi pada keanekaragaman atau keindahan alam dan budaya. Hal ini sejalan dengan pendapat Dewi (2011) yang mengatakan, "Dengan keunggulan branding daya tarik wisata Indonesia yang berbasis alam dan budaya, maka pembangunan destinasi yang berkelanjutan menjadi pilihan yang strategis untuk membangun kepariwisataan Indonesia sekaligus merespon tren eco-wisatawan yang semakin menguat."

Geopark, geotourism, geoconservation atau taman bumi adalah strategi manajemen geoheritage berbasis pada ide bahwa sumber geologi memiliki nilai tinggi terhadap keilmuan dan parawisata serta resiko ancaman kerusakan dari aktivitas manusia (Gray, 2005). Konservasi 
geopark yaitu pelestarian yang dinamis dan diyakini akan meningkatkan daya tarik turis untuk berkunjung dan 9 nilai geosaintifiknya yaitu meningkatnya fitur geologi dan morfologi, proses, situs dan specimen (Burek 2014).

Pengembangan dan pengelolaan geopark telah dibuktikan oleh Cina menghasilkan devisa Negara mencapai U\$ 90 juta pada tahun 2004 (Xun. 2007). Pendapatan ini bersumber dari pengembangan ekonomi berbasis wisata (lingkungan dan social budaya) dan membuka dan menyediakan lapangan pekerjaan untuk 5000 orang. Pengembang geopark di NTB menjadi penting dikarenakan sesuai dengan misi Provinsi NTB menjadi tujuan wisata dunia. Amphitheater geopark Tambora, bukit serta padang savana dan lingkungan alam di kawasan Tambora menghasilkan pemandangan yang eksotis sehingga menjadikan kawasan ini berpotensi untuk dijadikan cagar alam geologi dan hayati. Saat ini keberadaan sumber daya alam hayati dikawasan geopark Tambora semakin terancam dengan meluasnya kerusakan hutan dan berpotensi berdampak pada kepunahan spesies prioritas. Aktivitas penebangan liar yang dilakukan oleh masyarakat juga menambah buruk kerusakan cagar alam geologi dikawasan ini dan kelestarian lingkungan. Dalam upaya kelestarian warisan alam amphitheater geopark Tambora mutlak diperlukan pola aktivitas konservasi geologi dan biologi (geoconservation) serta pemberdayaan masyarakat lokal meliputi bidang social, budaya, ekonomi yang mendorong terciptanya upaya pelestarian sumber daya alam yang berkesinambungan. Cara yang paling efisien untuk mencapai geoconservation adalah meningkatkan kesadaran masyarakat tetang situs geoheritage (keilmuan, estetika, pendidikan, kebuadayaan pariwisata, ekonomi dan intrisik) dikawasan geopark Tambora.

Untuk menunjang pemenuhan fasilitas pariwisata di kawasan geopark Tambora yang menarik dan ramah lingkungan, sehingga perlu dikembangan pondok penginapan bagi wisatawan yang berkunjung dalam bentuk homestay. Minat wisatawan sekarang ini cenderung memilih wisata yang bernuansa alam.
Mereka lebih santai dengan menikmati pemandangan alam sekitar. Pemerintah sekarang lebih mengembangkan kegiatan pariwisata alam (UNESCO. 2009).

Pariwisata tinggal bersama atau homestay' semakin popular sekarang ini. bukan saja di kalangan rakyat setempat tetapi juga wisatawan mancanegara sehingga mampu mendorong jumlah wisatawan yang datang ke tempat wisata. Dalam konsep hamestay para wisatawan baik domestik maupun mancanegara akan dipersembahkan dengan suasana kehidupan kampung yang damai yang jarang diperoleh oleh masyarakat yang sudah terbiasa hidup di kota atau negara-negara yang sudah maju. Untuk mewujudkan dan menampilkan konsep pariwisata agrowisata, setiap wisatawan yang menginap di situ bukan saja dapat menikmati keindahan alam yang natural tetapi juga dapat menimba pengalaman kehidupan sehari-hari masyarakat. Pada penelitian ini bertujuan untuk mengidentifikasi sumberdaya alam dan sumberdaya manusia yang ada di kawasan geopark Tambora untuk menganalisis sebaran dan pengelolaan homestay berdasarkan kondisi kekayaan geopark Tambora.

\section{METODE PENELITIAN}

Penelitian dilaksanakan di wilayah kawasan Geopark Tambora yang meliputi 8 desa yang termasuk dalam kawasan inti Geopark Tambora yaitu desa Kadindi, desa Tambora, desa Oi Bura, desa Labuan Kananga, Desa Kawinda Toi, Kawinda Na,e dan Piong. Waktu penelitian dilakukan pada bulan Maret 2018 sampai Juni 2018. Alat dan bahan yang digunakan : alat tulis menulis,, tally sheet, panduan wawancara, meteran, sedangkan alat pelengkap lainya tape recorder, komputer beserta perlengkapanya, peta, kamera. Bahan yang digunakan dalam penelitian ini : data-data dokumen pendukung penelitian seperti data demografi dan lahan. Metode yang digunakan untuk mencapai tujuan dan sasaran yang telah ditetapkan meliputi metode pengumpulan data, metode pengolahan data, metode pembahasan dan perumusan konsep. Pemilihan informasi dilakukan dengan menggunakan teknik snowball (bola salju) dengan 
terlebih dahulu menentukan informan kunci (Key Informan) yang dianggap memiliki kecukupan informasi mengenai masyarakat dan kebudayaan di daerah penelitian (Singarimbun, 2010). Informan kunci bisa saja merupakan tokoh adat setempat, tokoh agama, tokoh masyarakat, kepala desa pimpinan kelompok masyarakat seperti Ketua RT, Ketua RW, Kepala Dusun. Tokoh masyarakat yang telah hidup lama dan menjadi yang dituakan atau mengerti seluk beluk tradisi masyarakat secara umum maupun secara khusus. Setelah informan kunci ditentukan, sesuai dengan istilahnya, teknik snowball diterapkan dengan cara "menggulir" informasi yang ditemukan sehingga dapat menuntun peneliti menuju informan lainnya yang mampu memberikan informasi/data yang dicari. Untuk menganalisa data ini menggunakan teknik analisa data kualitatif. Menurut Maryaeni (2005:75) analisis merupakan kegiatan: (1). Pengurutan data sesuai dengan rentang permasalaha atau urutan pemahaman yang ingin diperoleh; (2). Pengorganisasian data dalam formasi, kategori, ataupununit perian tertentu sesuai denn antisipasi peneliti; (3). Interpretasi peneliti berkenaan dengan signifikasi butir-butir ataupun satuan data sejalan dengan pembahasan yang ingin diperoleh; (4). Penilaian ataupun satuan data sehingga membuahkan kesimpulan baik atau buruk, tepat atau tidak tepat, signifikan atau tidak signifikan.

Analisis data dilakukan dengan mengikuti sifat umum dalam tahapan penelitian kualitatif menurut Usman dan Akbar (2006) sebagai berikut : (1) Mereduksi data, yakni merumuskan secara singkat dengan klasifikasi tertentu sesuai dengan informasi/data yang ditemukan di lapangan; (2) Penyajian data, yakni memaparkan informasi/data dalam sebuah tulisan sesuai dengan data yang telah direduksi pada tahap analisis pertama, dan tahap terakhir adalah; (3) Penarikan kesimpulan, yakni menentukan pokok jawaban sesuai dengan sajian data dilakukan pada tahap kedua.

\section{HASIL DAN PEMBAHASAN}

\section{Deskripsi Potensi Geopark Tambora}

Berdasarkan pengamatan langsung dari lapangan mengambarkan bahwa Taman Nasional Tambora sudah berarli fungsi menjadi wahana wisata.hal ini dibuktikan dengan kujungan wisatawan yang selalu meningkatkan setiap tahunnya. Dilihat dari statusnnya Taman Nasional Tambora pada dasarnya di jadikan Cagar Alam, Suka Margasatwa dan Taman Buru. Yang diman pada tempat tersebut mempunyai keanekaragaman jenis tumbuhan dan satwa yang keberadaanya perlu dilindungi dan perkembangganya berlangsung secara alami. Taman nasional merupakan kawasan pelestarian alam yang memiliki ekosistem asli yang memiliki keunikan tersendiri dan dikelola melalui sistem zonasi untuk dimanfaatkan bagi kepentingan pariwisata dan rekreasi alam selain untuk kepentingan pendidikan, penelitian, ilmu pengetahuan dan lain-lain. Penetapan atau penunjukan suatu kawasan menjadi taman nasional harus memenuhi kriteria antara lain : memiliki luasan yang cukup, memiliki ekosistem asli/unik serta memiliki keanekaragaman hayati yang tinggi.

Potensi wisatawan yang menuju pendakian gunung tambora memiliki 4 jalur pendakian yaitu: Jalur Pancasila, Jalur Kawinda To'i, Jalur Kore, Jalur Doropeti. Menurut hasil survey yang telah dilakukan bahwa jalur pancasila merupakan jalur yang banyak dilewati oleh para pendaki Gunung Tambora. Sebelum mendaki melewati jalur ini, terlebi dahulu pendaki akan memasuki Dusun Pancasila, Desa Tambora, Kecematan Pekat, Kabupaten Dompu, Nusa Tenggara Barat. Kondisi jalur pancasila cukup landai akan tetapi jarak dari desa pancasila tersebut ke puncak Gunung Tambora sekitar kurang lebih $20 \mathrm{~km}$. Jalur pancasilamemiliki 5 pos dan kondisi topografi yang sangat curam akan ditemui setelah melewati pos 5. Jenis vegetasi yang dapat dijumpai dijalur pancasila yaitu vegetasi hutan alam, hutan cemara, dan akan ditemukan bunga edelweiss di bibir kaldera. Jalur pancasila tidak terdapat savana seperti jalur-jalur lainnya. Hanya saja saat melewati pos, akan dijumpai bukit-bukit yang 
ditumbuhi rumput dan bunga edelweiss. Hutan alam yang terdapat pada jalur ini memiliki tingkat kerpatan tajuk yang cukup tinggi mulai dari tumbuhan bawah sampai pohon. Sumber air yang ada di jalur ini yaitu berada di pos 1 dimana sumber air tersebut merupakan salah satu sumber air yang dapat digunakan untuk menghidupi kebutuhan desa pancasila. Selain itu sumber air juga ada di pos 2 yaitu berupa sungai yang tidak terlalu lebar, relatif dangkal dan jerni. Sumber air juga dapat ditemukan di pos 3 dengan intesitas yang sedikit karena air tersebut mengalir setetes demi setetes. Sumber air lainya yaitu kumbangan yang ada disekitar pos 5 dan biasanya digunakan untuk minum satwa liar yang ada di sekitarnya. Jalur pancasila sangat terkenal dengan kopi kopi tambora, dikarenakan terdapat kebun kopi di perbatasan anatara desa dengan jalur menuju puncak gunung Tambora (Maksimus. 2015).

\section{Potensi Produk Wisata Kawasan Geopark Tambora}

Didasarkan atas perbedaan morfografi, morfogenesis dan morfokronologi, dipisahkan menjadi : Morfologi Vulkanik Tua, terdapat di sekitar Gunung Labumbum, dicirikan dengan tingkat erosi sedang-kuat, batuan pembentuk berupa lava dan endapan aliran piroklastik yang sudah mengalami pelapukan tingkat lanjut; Morfologi Perbukitan Sedimen, terdapat di sebelah utara Gunung Tambora, dicirikan dengan pola aliran sungai relatif paralel dengan tingkat erosi sedang-kuat, batuan penutup berupa batu gamping; Morfologi Tambora, menempati bagian tengah daerah penelitian, memperlihatkan bentuk kerucut terpancung. Pada bagian puncaknya terdapat kaldera berdiameter $6 \times 7 \mathrm{~km}$ dengan kedalaman kaldera sekitar 900-1.100 meter. Dasar kaldera merupakan daerah datar yang terkadang digenangi air dan dibagian selatan tenggaranya terdapat kerucut kecil Doro Api Toi (Zulharman, 2017).

\section{Wisata Alam}

Karekteristik bentang lahan yang umumnya berupa areal pengunungan dengan tutupan vegetasi rapat memiliki kelerengan sedang sampai curam serta adanya peninggalan sejarah akibat letusan yang terjadi pada tahun 1815, maka objek daya tarik wisata alam yang dapat dikembangkan di kawasan Gunung Tambora antara lain : Kaldera : Gunung Tambora merupakan salah satu dari tiga gunung api aktif selain Gunung Rinjani dan Gunung Sangiang. Gunung Tambora terbentuk awalnya pada 200 juta tahun yang lalu dimana gunung ini hanya berupa aliran lava kawah pusat yang membentuk gunung api perisai dengan ketinggian +1.800 mdpl dengan volume $200 \mathrm{~m} 3$. Jungle Tracking : Menjelajah hutan merupakan salah satu bentuk wisata berbasis alam. Kegiatan menjelajah hutan atau sering dikenal dengan nama jungle tracking dapat dilakukan di kawasan Gunung Tambora. Kegiatan ini didukung kondisi tutupan vegetasi yang masih cukup rapat dengan kondisi sekitar jalur penjelajahan yang cukup sejuk dan nyaman. Kegiatan jungle tracking tersebut dapat dilakukan pada empat pintu pendakian yaitu Piong (Kore), Kawinda toi, Doroncanga dan Pancasila. Wisata Tirta :Kawasan Gunung Tambora memiliki tutupan vegetasi yang cukup rapat dan merupa kan daerah tangkapan air bagi daerah sekitarnya. Karena merupakan daerah tangkapan air maka di kawasan Gunung Tambora terdapat beberapa alur sungai salah satunya adalah sungai Oi Marai yang ada di Desa Kawinda Toi. Wisata Minat Khusus : Kondisi kawasan dengan potensi alam yang sangat memungkinkan untuk dikembangkan sebagai objek daya tarik wisata membuat kawasan yang saat ini berstatus sebagai Cagar Alam, Suaka Margasatwa dan Taman Buru ini memiliki peluang pengembangan pariwisata yang sangat menjanjikan (Seubsamarn,2009). Wisata Ilmiah : Selain wisata alam, wisata alam dan wisata minat khusus, kawasan Gunung Tambora juga bisa dikembangkan sebagai pusat wisata ilmiah seperti interpretasi jenis tumbuhan dan atau satwa yang ada di kawasan Gunung Tambora.

Adapun matrik kegiatan wisata yang dapat dikembangkan di kawasan Gunung Tambora sebagai berikut : 
Tabel 1. Matrik Kegiatan Wisata Yang Dapat Dikembangkan di Kawasan Gunung Tambora

\begin{tabular}{|c|c|c|c|}
\hline No & Jenis Wisata & Bentuk Kegiatan & Sarana \\
\hline 1 & Wisata alam & $\begin{array}{l}\text { Jungle Treking } \\
\text { Berkemah } \\
\text { Photo Hunting } \\
\text { Rekreasi } \\
\text { Bersepeda } \\
\text { Outbond } \\
\text { Animal watching } \\
\text { Atraksi Rusa } \\
\end{array}$ & $\begin{array}{l}\text { Jalan trail wisata, jalan setapak, } \\
\text { MCK, bangku, Lapangan } \\
\text { terbuka, arena bermain, } \\
\text { shelter, menara pengawas, } \\
\text { fasilitas outbond, mushola, } \\
\text { sepeda, binokuler, tenda }\end{array}$ \\
\hline 2 & Wisata tirta & $\begin{array}{l}\text { Mandi di sungai } \\
\text { Susur sungai } \\
\text { Bird watching } \\
\end{array}$ & Shelter, MCK \\
\hline 3 & Wisata minat khusus & $\begin{array}{l}\text { Spritual keagamaan } \\
\text { Acara adat lokal } \\
\text { Pentas seni dan budaya }\end{array}$ & $\begin{array}{l}\text { Shelter, menara pengawas, } \\
\text { aula, teater terbuka }\end{array}$ \\
\hline 4 & Wisata ilmiah & $\begin{array}{l}\text { Studi tour } \\
\text { Studi banding } \\
\text { Penelitian } \\
\end{array}$ & $\begin{array}{l}\text { Pustaka konservasi, stasiun } \\
\text { penelitian, perlengkapan audio } \\
\text { visual }\end{array}$ \\
\hline 5 & Wisata budaya & $\begin{array}{l}\text { Terdapat } 2 \text { jenis Rimpu, yaitu Rimpu Pida } \\
\text { (digunakan oleh gadis) dan Rimpu Ampe } \\
\text { (digunakan oleh wanita yang sudah } \\
\text { menikah) Ritual budaya dan upacara }\end{array}$ & Situs budaya \\
\hline
\end{tabular}

Sumber: Hasil Identifikasi tahun 2018

\section{Kajian Geohomestay}

Homestay merupakan fasilitas yang harus disediakan pdaa kawasan wisata geopark karena pengunjung ingin menikmati serta berbaur dengan kondisi alam, budaya dan sosial masyarakat di kawasan geopark. Oleh Karena itu pola persebaran homestay harus mendukung setiap geosite yang ada yaitu disetiap geiosite harus ada homestay yang tersedia dan terdapat informasi mengenai geosite tersebut sehingga pengunjung yang menginap dapat memeperoleh informasi keseluruhan geiosite yang dikunjungi pada homestay yang ditinggali.

\section{Sebaran Homestay Di Geopark Tambora}

Sebaran homestay yang ada di kawasan Geopark Tambora yaitu sebagai berikut :

Tabel 2. Sebaran Homestay Yang Ada

\begin{tabular}{clclll}
\hline No & Nama Homestay & Jumlah & Bentuk & Letak & Pemilik \\
\hline 1 & Homestay Pribadi & 3 & Kost-kostan & Doro Peti & \\
\hline & Homestay Pribadi & 4 & Kost-kostan & Kadindi & \\
\hline 2 & Calabai & 4 & Kost-kostan & Calabai & \\
\hline 3 & Homestay Kamsul & 1 & Rumah Gazebo & Desa Tambora & Kamsul \\
\hline 4 & Homestay Pondok Petualang & 1 & Rumah Gazebo & Desa Tambora & Saiful \\
\hline 5 & Homestay pribadi & 1 & Rumah Gazebo & Labuan Kananga & H. Suaeb \\
\hline 6 & Homestay pribadi & 1 & Rumah Gazebo & Kawasan KTM & H. Suaeb \\
\hline 7 & Homestay Pondok Konservasi & 1 & Rumah Gazebo & Kawinda To.i & TNT \\
\hline 8 & Homestay Dole & 1 & Rumah Tinggal & Piong & Dole \\
\hline
\end{tabular}

Secara umum fasilitas yang ada pada beberapa homestay yang ada masih standart dan masih belum mencerminkan homestay yang berbasis Geopark. Kebanyakan homestay masih dikelola secara konvensional dan ala kadarnya dengan manajemen tunggal oleh masing-masing pemilik

homestay. Rata-rata biaya sewa homestay berkisar antara Rp. 100.000 - Rp. 250.000 per hari dengan fasilitas kamar mandi, ruang tidur seta makanan yang berbayar. Berdasarkan beberapa konsep dapat disimpulkan bahwa menurut Lashley dan Morrison pada akomodasi homestay 
terdapat akomodasi farmstay, beberapa fasilitas hotel kecil, keluarga pemilik serta tempat tidur dan makanan di mana wisatawan atau tamu membayar langsung atau tidak langsung untuk tinggal di rumah-rumah pribadi tersebut. Menurut Lynch pada akomodasi homestay, ruang privat dalam rumah dibuka menjadi ruang publik, berbeda dari akomodasi lain yang ruang privatnya hanya terbuka bagi staf saja. Rivers menyatakan bahwa pada akomodasi homestay utilitas dan makanan biasanya disertakan, lama menginap bisa harian, mingguan, bulanan, bahkantidak terbatas kecuali ditentukan oleh pemilik rumah.

Letak dan sebaran homestay belum berbasis geosite geopark yang ada sehingga belum memperhitungkan jarak dengan atraksi wisata dan antar atraksi serta konektifitas antar atraksi serta fasilitas umum. Sebaran homestay masih bersifat acak serta masih sangatimim informasi tentang keberadaanya baik dimedia internet maupun papan reklame.

\section{Pola Sebaran dan Profil kawasan Geohomestay Berbasis Geosite}

Fenomena geologi di kawasan Gunungapi Tambora cukup beragam, mulai dari bukti aktivitas vulkanik baik pra ataupun pasca letusan 1815, singkapan batuan dan fosil, pulau kecil, danau, pantai dan air terjun. Sebaran homestay mengikuti potensi dan sebaran geosite yang ada sehingga aksessibilitas setiap geosite dengan homestay yang ada masihterjangkau serta informasi atau model homestay disesuaikan dengan geosite yang berada di dekatnya.

Pembahasan eksternal merupakan analisis terkait hubungan bangunan terhadap lokasi dan lingkungan sekitar. Analisis eksternal terdiri atas beberapa sub bagian analisis yaitu berupa analisis lokasi, perletakan, orientasi, sirkulasi, vegetasi dan zoning pada kawasan. Site perancangan berada di seluruh geosite Geopark Tambora. Lokasi perancangan kawasan homestay dipilih berdasarkan kriteria yang sesuai. Berdasarkan tinjauan teori tentang homestay, adapun kriteria lokasi perancangan adalah sebagai berikut: 1) Umumnya berlokasi di tempat-tempat yang mempunyai potensi wisata, misalnya tempattempat dengan pemandangan alam yang indah seperti pantai, pegunungan, tepi sungai, tepi danau; 2) Berada di tempat-tempat yang jauh dari pusat kota khususnya tidak dirusak oleh keramaian kota, lalu lintas padat dan bising serta polusi udara; 3) Berdekatan dengan daerah yang memiliki atraksi wisata dan kegiatan rekreasi karena merupakan tuntutan utama pasar dan berpengaruh pada harganya; 4) Perancangan homestay terletak di lokasi dengan potensi-potensi alam yang menarik dan kondisi lingkungan khas agar potensi tersebut dapat lebih dioptimalkan pada rancangan.

Adapun berikut ini merupakan tabel analisis pemilihan site perancangan kawasan:

Tabel 3. Pertimbangan Pemilihan Site Perancangan homestay

\begin{tabular}{cl}
\hline $\begin{array}{l}\text { Sebaran homestay pada } \\
\text { kawasan geosite utama }\end{array}$ & Kelebihan \\
\hline 1 & + Keseluruhan lahan adalah lahan kosong berupa kebun \\
& + Sumber air berlimpah dan dan tidak pernah kering di kawasan \\
\hline 2 & + Banyak terdapat lahan adalah lahan kosong berupa kebun \\
& + Sumber air berlimpah dan dan tidak pernah kering di kawasan \\
& + Terdapat permukiman penduduk \\
& + Dekat dengan perkampungan \\
& + Terdapat akses dermaga \\
& + Terdapat beberapa area lahan kosong pada area pinggir permukiman \\
& + Sumber air berlimpah dan dan tidak pernah kering di kawasan \\
& + Terdapat permukiman \\
& + Terdapat sirkulasi jalan \\
& + Terdapat sumber aliran listrik PLN \\
& + Banyak terdapat lahan adalah lahan kosong berupa kebun \\
& + Terdapat sirkulasi jalan + Terdapat sumber aliran listrik PLN \\
\hline 4
\end{tabular}




\begin{tabular}{ll}
\hline 5 & + Terdapat permukiman penduduk \\
& + Terdapat sirkulasi jalan beton \\
& + Terdapat sumber aliran listrik PLN \\
\hline 6 & + Banyak terdapat lahan adalah lahan kosong berupa kebun \\
& + Terdapat sirkulasi jalan \\
& + Terdapat sumber aliran listrik PLN \\
& + Banyak terdapat lahan adalah lahan kosong berupa kebun \\
& + Terdapat sirkulasi jalan \\
& + Terdapat sumber aliran listrik PLN \\
\hline
\end{tabular}

Berdasarkan pertimbangan lokasi tersebut maka perancangan kawasan homestay lebih di tempatkan pada kawasan 7 Geosite utama. Hal ini dikarenakan 7 geosite merupakan daerah potensial yang memilikikases baik dan berdekatan dengan geosite pendukung disekitarnya dan dapat dimanfaatkan untuk perancangan akomodasi ,selain itu lokasi berbatasan langsung dengan perkampungan serta terdapat akses jalan raya dan air bersih yang sangat diperlukan dalam pertimbangan perancangan bangunan komersial (Nabillah, 2018).

Pada setiap homestay memuat informasi yang bekaitan dengan antara lain sebagai berikut : 1) Tema geologi sesuai dengan potensi geosite yang

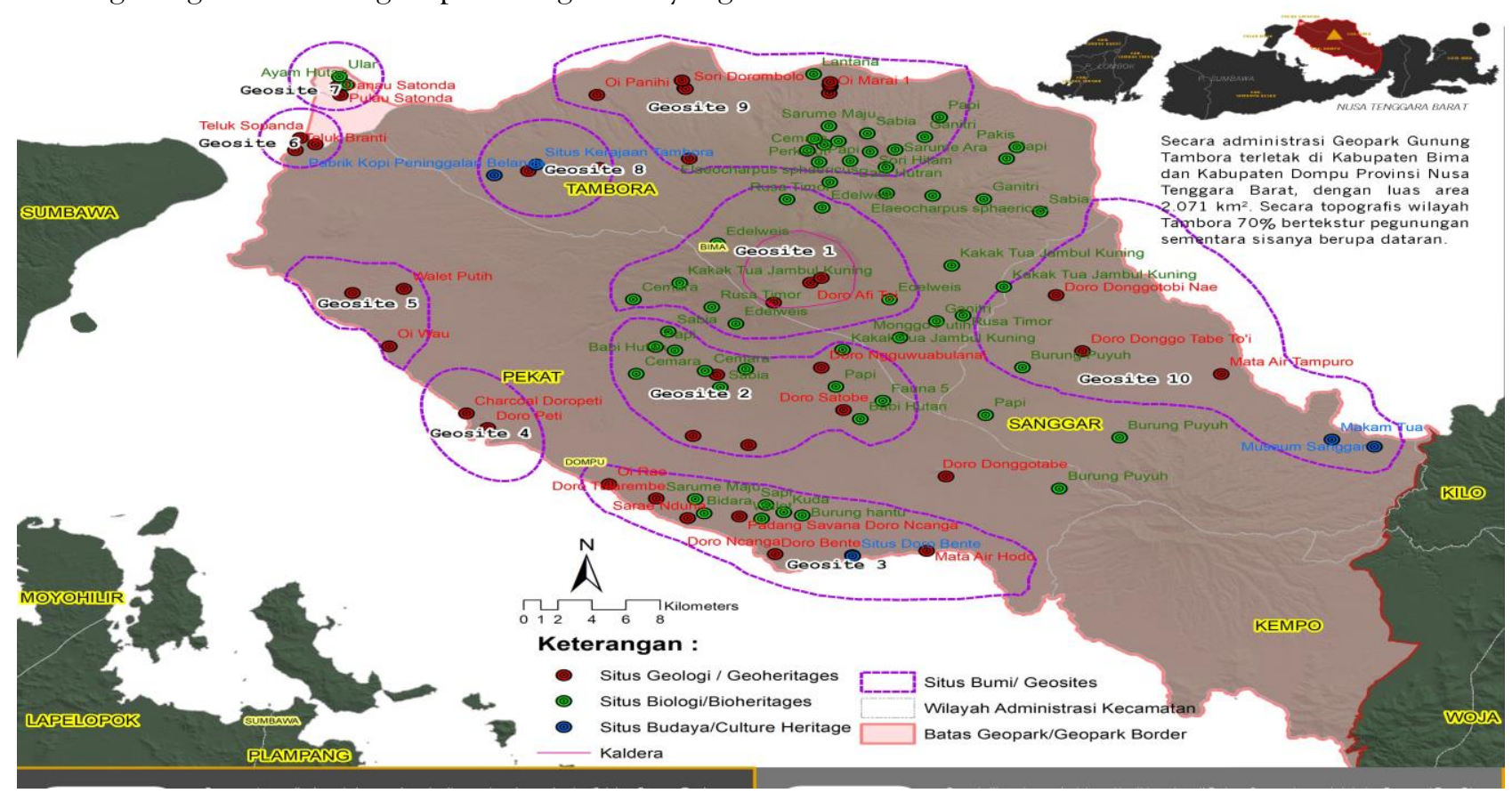

Gambar 1. Peta sebaran geosite geopark tambora sebagai referensi sebaran geohomestay ada di sekitarnya. Tema geologi ini disesuaikan dengan potensi atraksi geosite dapat yang menjadi basis homestay yaitu terdapat 7 basis homestay berdasaran aksesibiltas dan jarak antar geosite; 2) Informasi geologi setiap geosite yang ada pada sekitar homestay. Informasi yang terdapat pada setiaphoestay harus berbasis potnsi geosite yang ada di sekitarnya; 3) Bentuk penyajian informasi geologi pada setiap homestay berbasis geosite. Bentuk penyajian informasi dapat berupa peta titik geosite, fotofoto geosite serta majalah atau poster yang mendeskripsikan potensi geosite yang ada. 


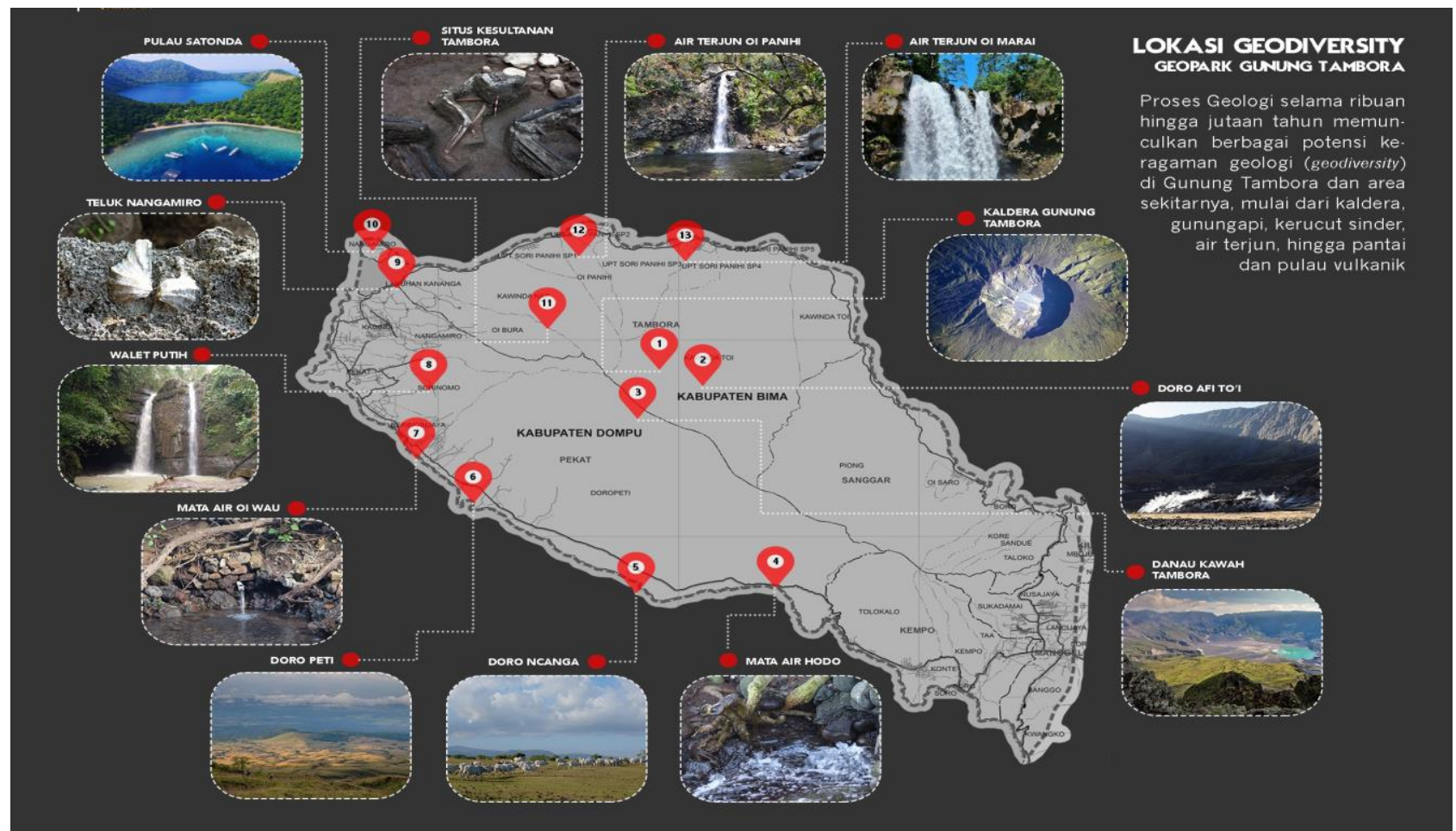

Gambar 2. Peta sebaran atraksi wisata geopark tambora sebagai referensi sebaran geohomestay

Sebaran homestay berdasarkan akses terhadap geosite antara lain:

Deskripsi dan Profil kawasan Geohomestay Pada Geosite 1 (Doro Peti)

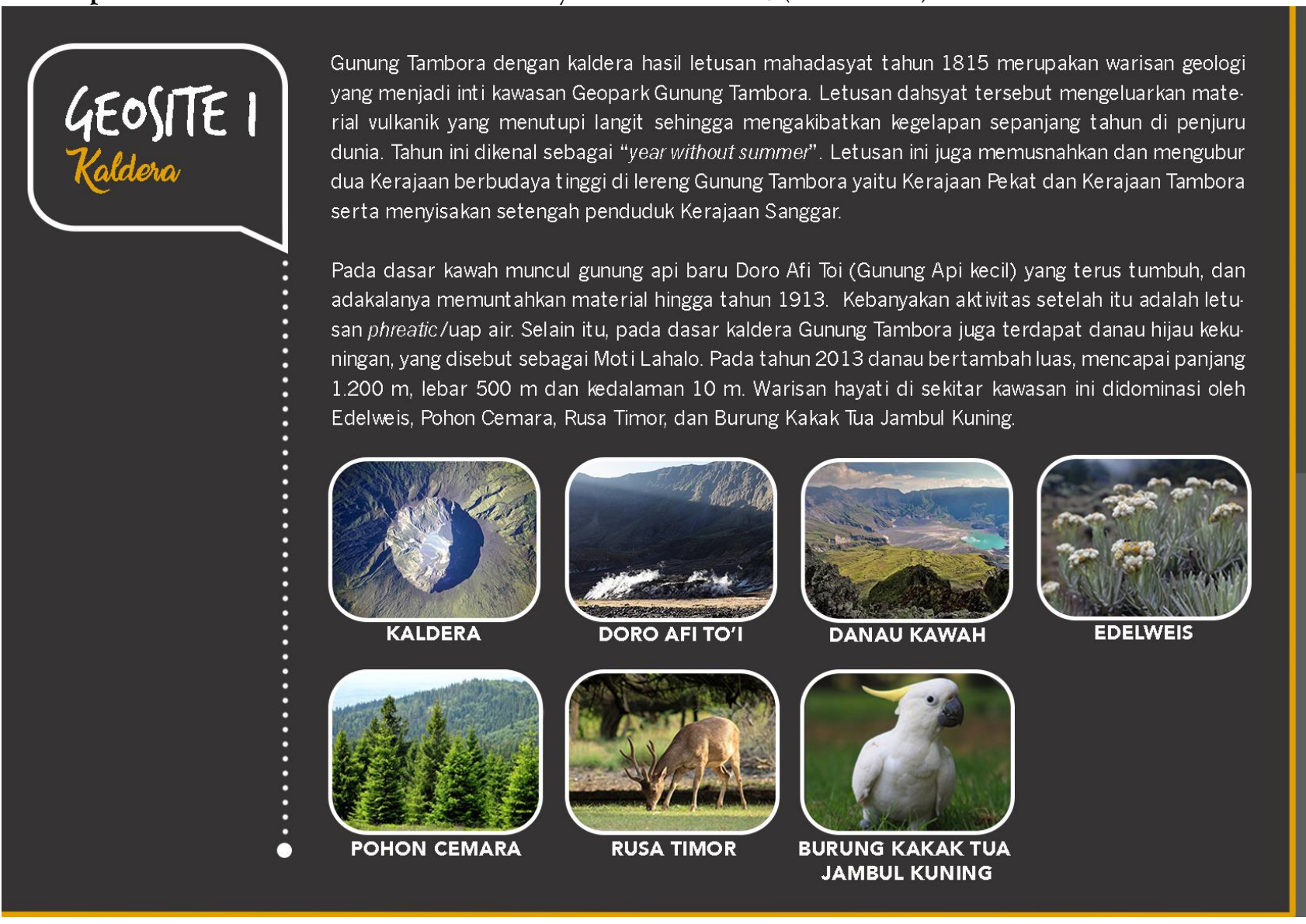

Gambar 3. Potensi atraksi wisata pada geosite 1 


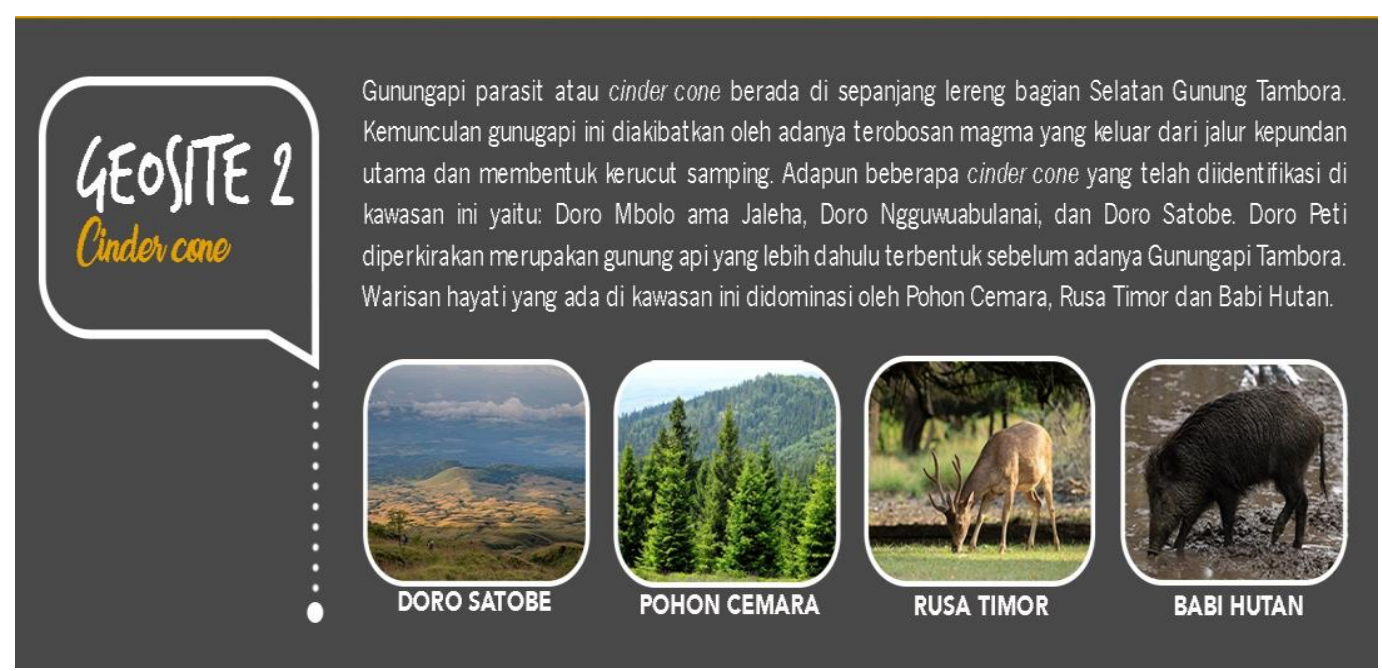

Gambar 4. Potensi atraksi wisata pada geosite 2

Berdasarkan gambar 3 dan 4 di atas bahwa potensi yang ada pada geosite 1 dan 2 merupakan potensi primer kawasan geopark tambora,oleh karena itu harus didukung dengan fasilitas homestay agar wisatawan dapat menikamti atraksi pada geosite tersebut dalam waktu beberapa hari karena sngat luas. Letak homestay pada geosite 1 ini harus berada pada setiap jalur pendakian gunung Tambora karena atraksi wisata pada gosite 1 ini antara lain Kaldera, Doro Api Toi, Danau Kawah, Bunga Edhelweuis, Pohon Cemara sepanjnag jalur pendakian Pancasila dan Kawinda Toi dan

Deskripsi dan Profil kawasan Geohomestay Pada Geosite 3, 4 dan Geosite 5 (DORO NCANGA)

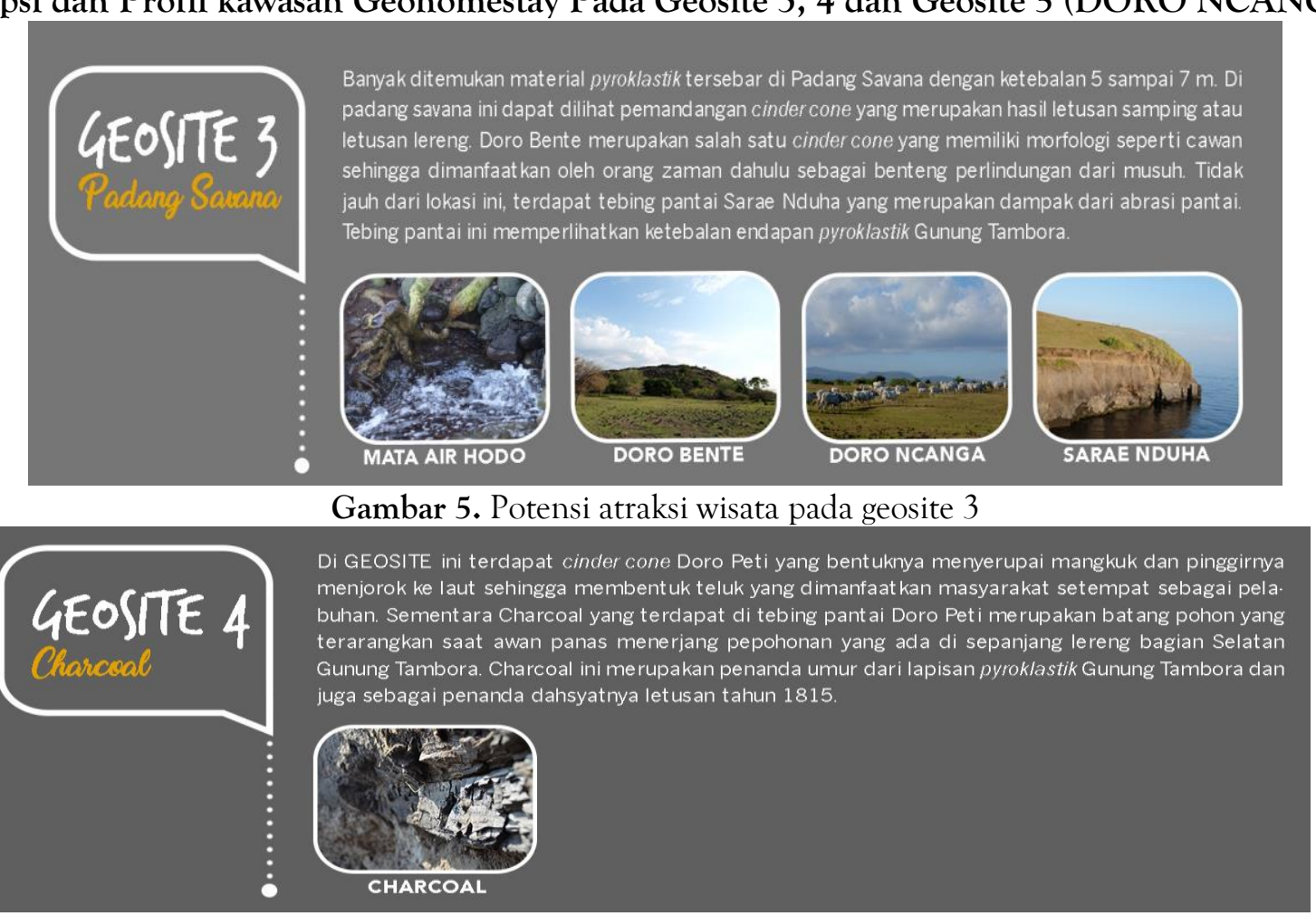

Gambar 6. Potensi atraksi wisata pada geosite 4 


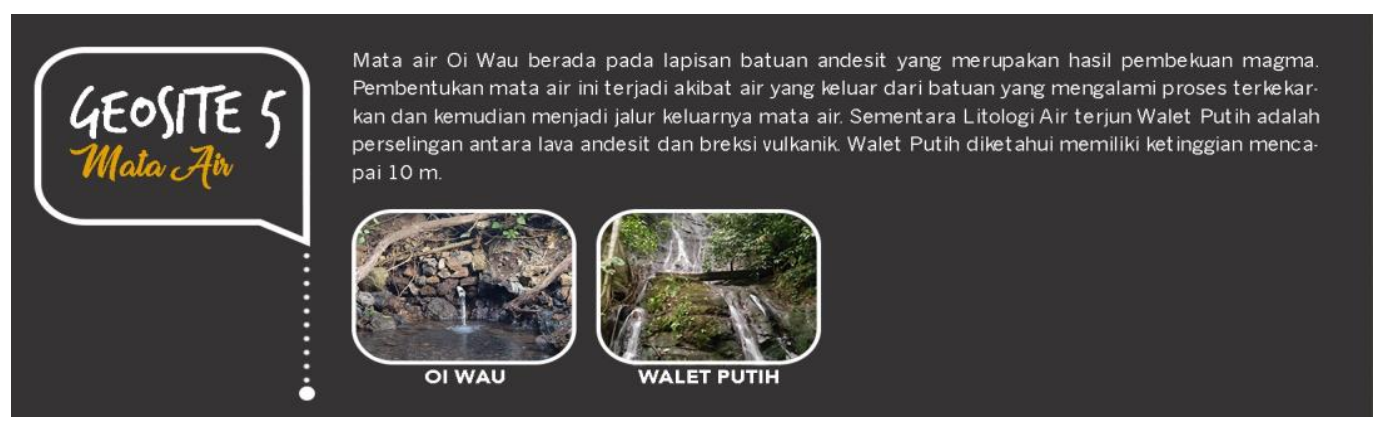

Gambar 7. Potensi atraksi wisata pada geosite 5

Kabupaten Dompu memiliki banyak destinasi wisata yang dapat dikunjungi wisatawan. Salah satunya Pantai Sarae Nduha atau biasa disebut sebagai Pantai Ombo. Pantai ini tidak jauh dari Doro Ncanga atau Gunung Tambora. Banyak wisatawan lokal yang berkunjung, terutama pada saat akhir pekan. Pantai ini terletak di Desa Doropeti Kecamatan Pekat Kabupaten Dompu dan belakangan menjadi destinasi utama wisatawan lokal. Lokasinya pun sangat mudah dijangkau. Apalagi pemandangannya sangat indah dan akan memanjakan siapa saja yang datang. Pantai ini juga dikelilingi oleh tebing. Di atasnya wisatawan dapat mendirikan tenda. Sangat cocok dijadikan sebagai destinasi untuk berlibur bersama keluarga. Pantai ini memiliki panorama yang indah dan sangat cocok dijadikan sebagai spot swafoto.

Deskripsi dan Profil kawasan Geohomestay Pada Geosite 6 (CALABAI)

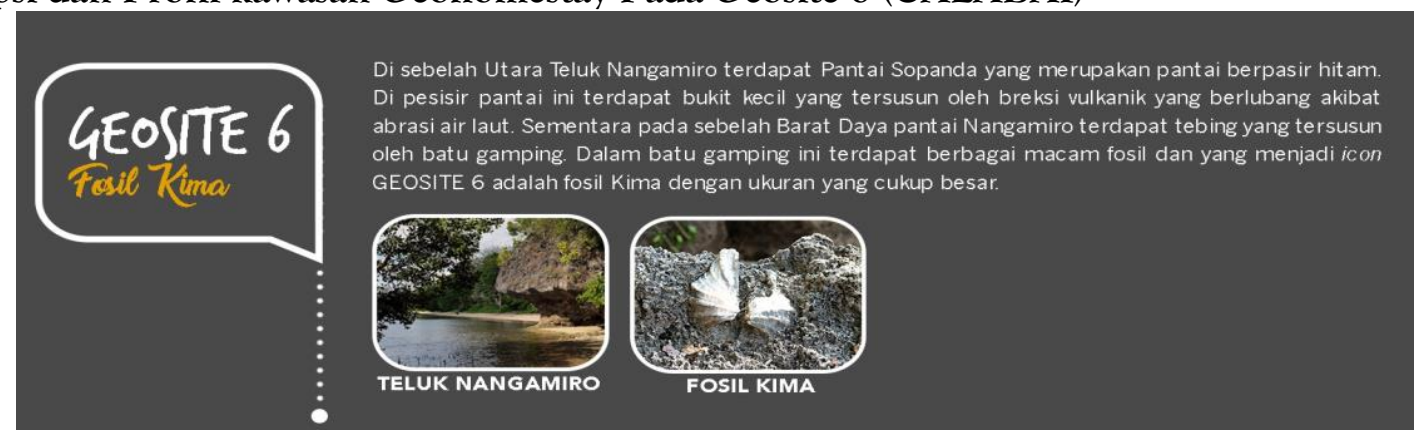

Gambar 8. Potensi atraksi wisata pada geosite 6

Deskripsi dan Profil Kawasan Geohomestay Pada Geosite 7 (Pulau Satonda)

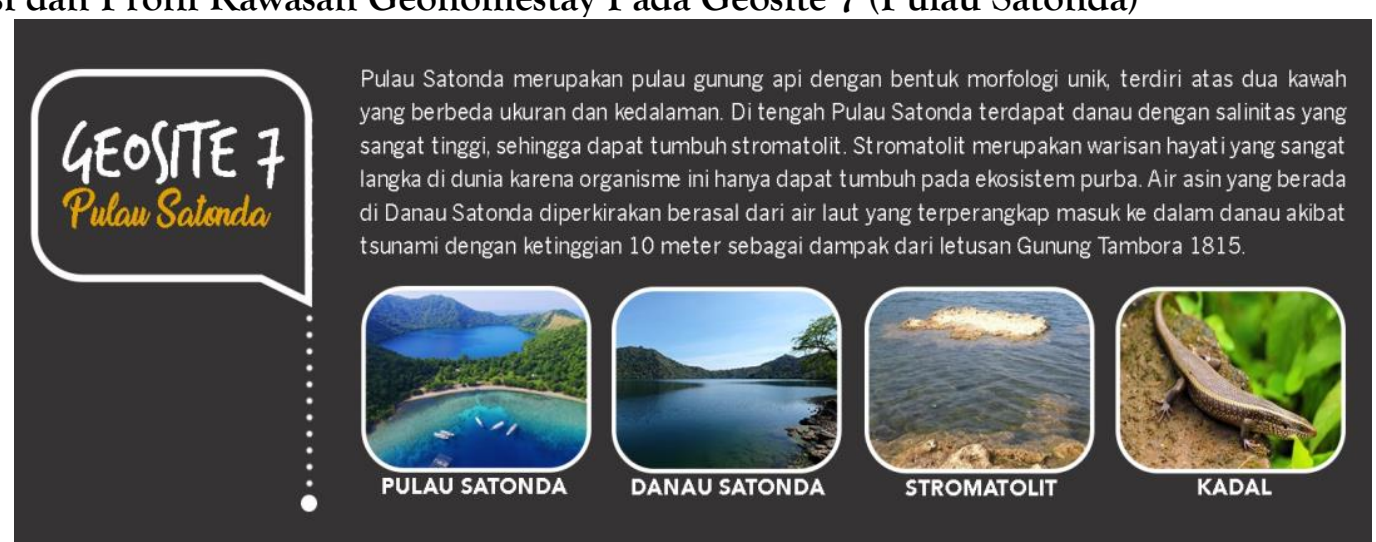

Gambar 9. Potensi atraksi wisata pada geosite 7

Berbagai pemandangan di Danau Pulau pengunjung menyatakan bahwa motivasi yang Satonda adalah terumbu karang, serta ikan kecil. Beberapa kegiatan wisata yang bisa dilakukan seperti snorkeling, scuba diving serta keadaan lingkungan laut yang masih alami. Motivasi Pengunjung Terhadap Pengembangan Ekowisata di Danau Pulau Satonda sebagian besar dari mendorong untuk mengunjungi Danau Puau Satonda yaitu dengan keindahan alam seperti danau air asing, menyelam yang dapat mengapung keatas ketika mandi di Danau Pulau Satonda dan keindahan terumbu karang serta keunikan dari danau satonda (yaitu pohon ritual). 


\section{Deskripsi dan Profil kawasan Geohomestay Pada Geosite 8 (Pancasila)}

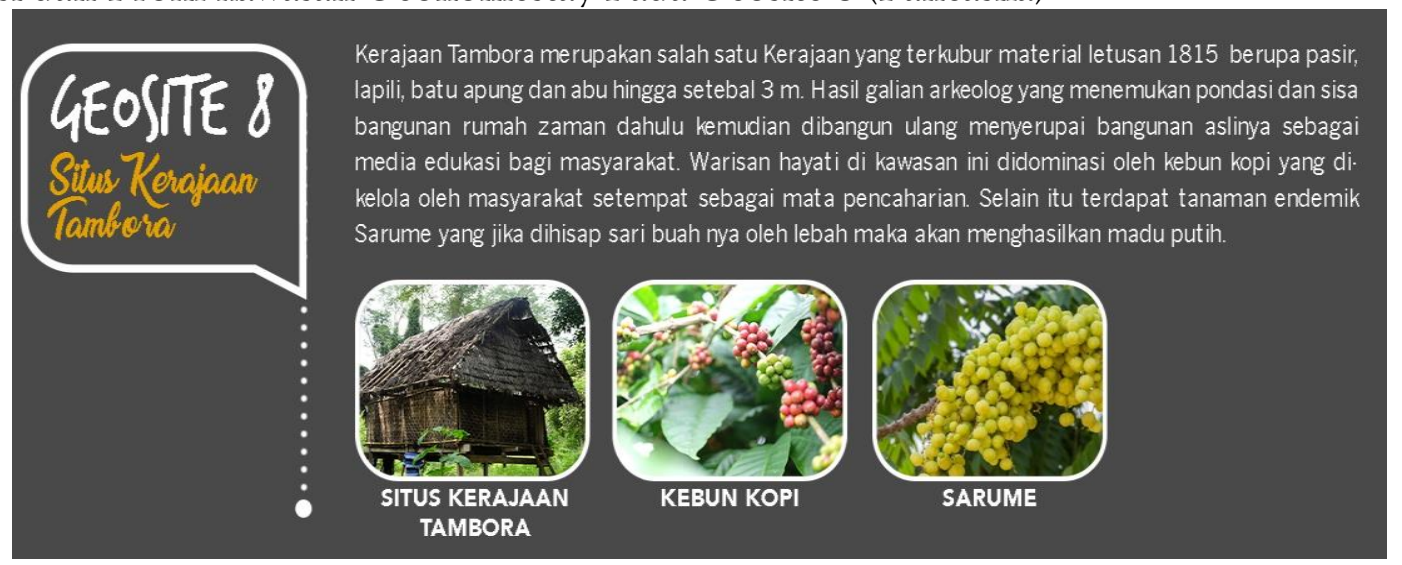

Gambar 10. Potensi atraksi wisata geosite 8

Geosite 8 merupakan kawasan bekas kerajaan tambora masa lampau. Kawasan geosite 8 ini terdapat berbagai macam situs sejarah peradaban kerajaan tambora serta menajdi salah satu jalur pndakian yaitu jalur pendakian pancasila. Home syat pada jalus pendakian pancasila ini terdapat 2 homestay yang sudah ada dan sudah terkonsep dengan baik. Fasilitas yang disediakan cukup memenuhi standar homestay, dimana pengununga langsung tingal pada akmar-kamar rumah gazebo yang berada dipekarangan rumah pemilik homestay. Namun homestay ini belum memiliki konsep pengelolaan yang baik sesuai dengan tema geopark atau geosite yang berada $\mathrm{d}$ sekitarnya. Oleh karena itu diperlukan konsep pengelolaan yang berbasisi geosite sehingga tersedia berbagai macam informasi yang berkaitan dengan geosite yang berada di sekitarnya serta penyiapan sarana dan prasarana yang memadai untuk kenyamanan para pengunjung.

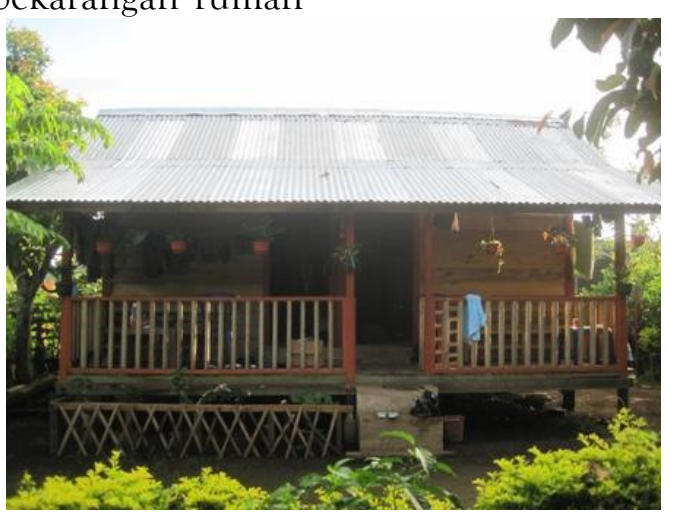

Gambar 11. Homestay pondok petualang geosite 8 (Dusun Pancasila)

Deskripsi dan Profil kawasan Geohomestay Pada Geosite 9 (Kawinda To.i)

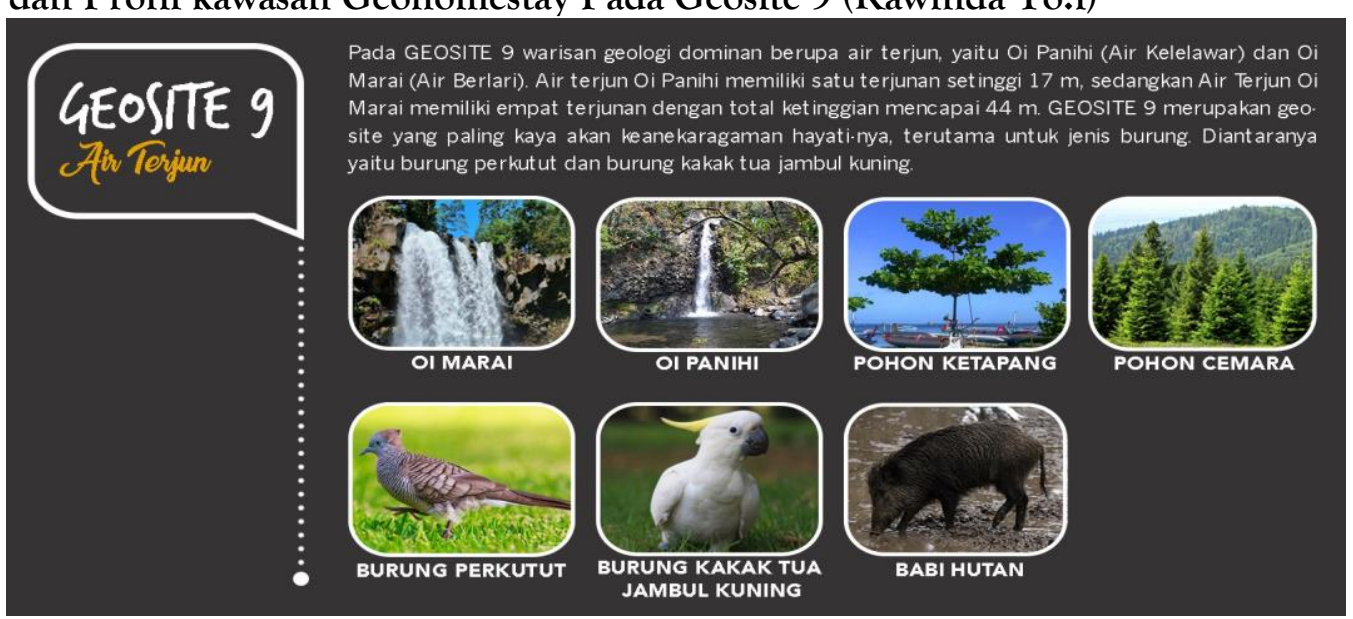

Gambar 12. Potensi atraksi wisata geosite 9 
Pada geosite 9 merupakan kawasan utara gunung tambora yang berada pada kecamatan tambora kabupaten bima. Potensi atraksi wisata yang ada antara lain air terjun oi oanihi, oi marai dan terdapat jalur pendakian Kawinda Toi. Leh karena itu ada geosite 9 memerlukan homestay sebagai tempat transit dan menginap bagi pengunjung yang akan menikmati atraksi wisasat pada geosite 9 ini. Lokasi penginapan atau homestay dapat ditempatkan pada beberapa titik sesuai dengan aksesibilitasnya terhadap atraksi wisata tersebut yaitu di kawinda na,e dan kawasan KTM Tambora serta di kawinda toi. Kawinda toi merupakan salah satu jalur pendakian tambora terdapat pula pos Taman Nasional Gunung Tambora. Homestay pada kawasan geosite 9 ini dapat dibuat sesuaikan

Deskripsi dan Profil kawasan Geohomestay Pada Geosite 10 (PIONG)

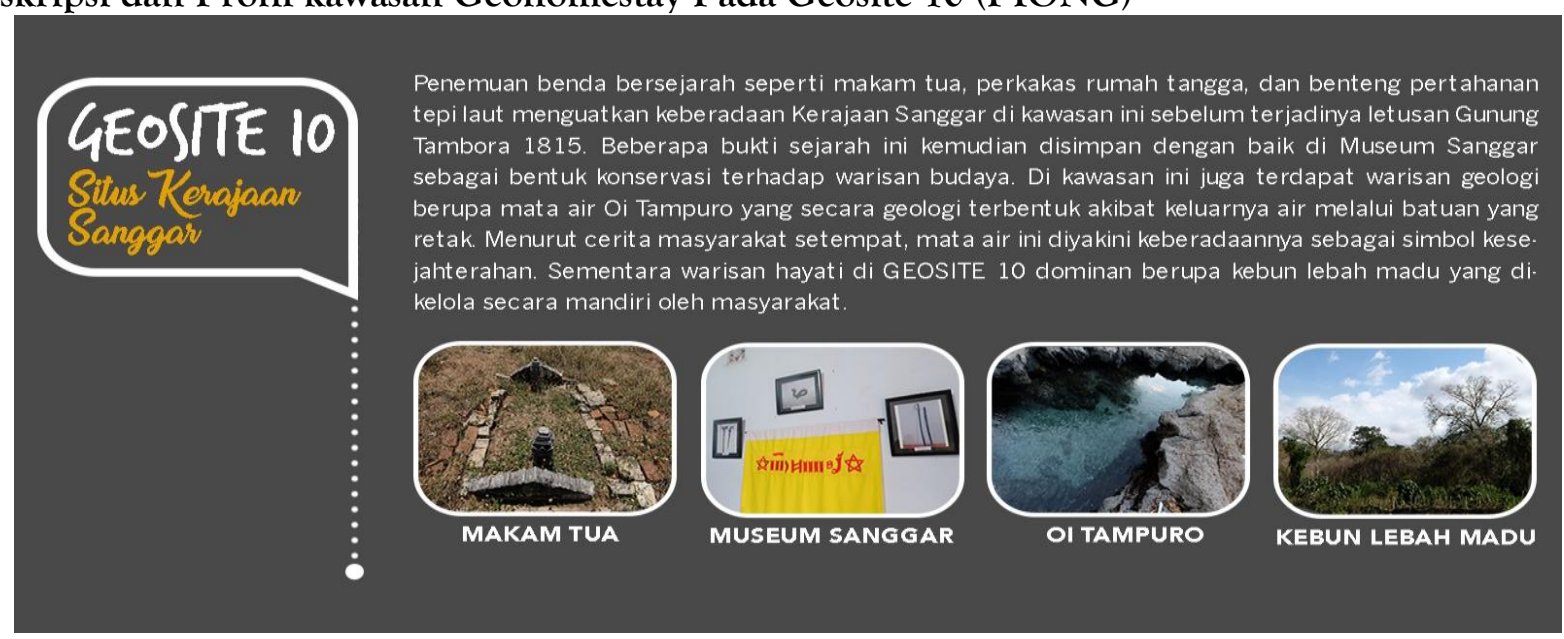

Gambar 13. Potensi atraksi wisata pada geosite 10 (Sanggar)

Potensi Atraksi Pendukung Homestay Dan Tema Homestay Geosite 10

Tabel 4. Objek/Destinasi Potensial di Sanggar

\begin{tabular}{|c|l|l|l|}
\hline No & Obyek Wisata & Lokasi & \multicolumn{1}{|c|}{ Potensi atraksi wisata } \\
\hline 1 & Pantai Piong & Desa Kore & $\begin{array}{l}\text { Wisata Bahari, Pantai Pasir putih, Camping Ground, } \\
\text { Wisata Kuliner }\end{array}$ \\
\hline 2 & Savana Piong & Desa Kore & Wisata Adventure \\
\hline 3 & Pantai Boro & Desa Boro & Wisata Bahari, Pantai Pasir putih, Wisata Kuliner \\
\hline 4 & So Loka & Desa Boro & Wisata Bahari, Pantai Pasir putih \\
\hline 5 & Dermaga Kore & Desa Kore & Dermaga transportasi laut \\
\hline 6 & Benteng Lainomos & Desa Boro & Bangunan kuno, Wisata Sejarah \\
\hline 7 & Mata Air Punti Moro & Desa Kore & Wisata alam, Wisata budaya \\
\hline 8 & Mata Air Tampuro & Desa Piong & Wisata alam, Wisata budaya \\
\hline 9 & Mata Air Kalero & Desa Boro & Wisata alam, Wisata budaya \\
\hline 10 & Mata Air Towan & Desa Boro & Wisata alam, Wisata budaya \\
\hline 11 & Rade Nae & Desa Boro & Cagar Budaya, Wisata Sejarah \\
\hline 12 & Istana Kore & Desa Kore & Cagar Budaya, Wisata Sejarah \\
\hline 13 & Makam Raja Sanggar & Desa Kore & Cagar Budaya, Wisata Sejarah \\
\hline 14 & Mata Air Campa Rimpu & Desa Kore & Wisata alam, Wisata budaya \\
\hline
\end{tabular}

Jurnal Pendidikan IPS, LPPM STKIP Taman Siswa Bima 


\begin{tabular}{|l|l|l|l|}
\hline 15 & Pasar Sanggar & Desa Kore & Pasar tradisional \\
\hline 16 & Labu Bili & Desa Piong & Pantai, Wisata Alam \\
\hline 17 & Doro Sagolo & Desa Boro & Wisata Alam, Spot photo \\
\hline 18 & Museum Kerajaan Sanggar & Desa Kore & Wisata Sejarah, Edukasi \\
\hline 19 & Pacuan Kuda Pantai & Desa Sandue & Wisata Adrenaline, Olahraga \\
\hline 20 & Dermaga Kore & Desa Kore & Wisata Alam, Pantai \\
\hline
\end{tabular}

Kerangka Teknis Model Bangunan Dan Tata berfungsi dengan baik., Dilengkapi bak tempat

\section{Kelola Geohomestay Di Geopark Tambora}

Berdasarkan uraian pada pembahasan di atas terdapat 7 sebaran kawasan homestay yang layak dikembankan pada geopark tambora. pengembangan geohomestay pada kawasan geopark Tambora setidaknya haru ememnuhi standar bangunan homestay yang layak dan mengutamakan kenyamanan. adapun kerangka teknis model bangunan dan tata kelola geohomestay tambora diuraikan sebagai berikut: Rumah :

Memiliki paling sedikit 1 (satu) kamar dan paling banyak 5 (lima) kamar yang khusus untuk disewakan. Sirkulasi udara dan pencahayaan yang cukup. Kondisi yang bersih dan terawat dilengkapi dengan Kunci kamar, Kaca rias, kursi, dan meja kecil, Lemari atau tempat meletakkan pakaian, Lampu penerangan, Tempat sampah, Kipas angin, Wifi, Informasi geologi (hiasan dinding), Alat ibadah, Kelambu, Menu sarapan pagi. Tempat tidur tertata dengan rapi dilengkapi dengan Bantal dengan sarungnya, Sprei, Selimut/bed cover, Papan nama dengan tulisan yang terbaca dan desain yang seragam, dipasang pada tempat yang terlihat dengan jelas, Terdapat informasi contact person dan alamat, Lampu pada papan nama, Kamar mandi dilengkapi dengan: Gantungan handuk, Tempat sampah, Kloset duduk, Tempat penampungan air, Saluran pembuangan air yang lancer, Air bersih yang mencukupi sesuai dengan jumlah kamar atau tamu yang menginap, Sabun cair dan tempat sabun yang menempel di tembok, Papan peta/informasi geologi di teras rumah, Booklet/leaflet informasi geosite/geopark Tambora. Dalam hal tersedia peralatan makan dan minum maka berada dalam kondisi bersih dan aman bagi tamu, sebagian terbuat dari bahan alam. Tersedia air minum, Kondisi dalam keadaan bersih dan terawatt, Dilengkapi peralatan dapur yang bersih, terawat, dan cuci yang bersih dan terawatt, Dilengkapi dengan saluran pembuangan limbah yang berfungsi dengan baik, Dilengkapi sistem pengolahan limbah yang ramah lingkungan, Dilengkapi tempat sampah tertutup ramah lingkungan, Tersedia air bersih yang diperlukan untuk membersihkan peralatan dapur serta peralatan makan dan minum.

\section{Pelayanan:}

Online (situs web, aplikasi online), Telepon, Pesan langsung/datang langsung, Buku tamu yang berisi informasi: Nama tamu, Alamat tamu, No KTP/Passport/SIM, Status perkawinan, Tujuan kunjungan, Datang dari mana, tempat tujuan kunjungan, Lama kunjungan. Sistem pembayaran tunai, Pembersihan lingkungan rumah tinggal dilakukan satu hari dua kali (pagi dan sore), Sistem pengolahan sampah yang ramah lingkungan dan terpadu (lingkungan). Pembersihan kamar tamu: Dilakukan setiap pagi hari (merapikan, menyapu, mengepel), Mengganti perlengkapan tempat tidur sesuai permintaan tamu, Tersedia informasi no telp penting: kantor polisi, pemadam kebakaran, rumah sakit/ambulans, puskesmas, no kontak pemilik homestay.

Dilakukan pengecekan terhadap peralatan dan fasilitas dalam homestay yang akan digunakan oleh tamu 1 (satu) jam sebelum tamu datang.

Tata tertib tamu selama tinggal di homestay, tersedia di setiap kamar, Tata cara penggunaan alat-alat dalam homestay, Mekanisme kompensasi yang diberikan atas keluhan tamu, Kertas kesan dan saran, dilengkapi informasi: 1) Nama tamu; 2) Alamat dan kontak email/telepon; 3) Kesan; 4) Saran

\section{Pengelolaan:}

Area khusus dalam rumah tinggal untuk keperluan administrasi dilengkapi fasilitas penunjang yang sederhana, Pengadministrasian 
pencatatan data identitas tamu terdokumentasi secara komputerisasi, Tersedia petunjuk tertulis untuk menghindari terjadinya kebakaran atau keadaan darurat lainnya.

Memiliki peralatan Pertolongan Pertama pada Kecelakaan (P3K), Menerapkan unsur Sapta Pesona meliputi: aman, tertib, bersih, sejuk, indah, ramah, dan kenangan. Mengikuti kegiatan peningkatan kemampuan pengelolaan yang diselenggarakan oleh unsur pemerintah, Mampu menjelaskan informasi geologis di wilayahnya.

\section{KESIMPULAN}

Berdasarkan hasilpenelitian, adapun beberapa kesimpulan yang bisa diambil, yaitu: 1) Kawasan geopark tambora terdiri dari 10 geosite utama yang memiliki daya tarik wisata; 2) Potensi wisata pada setiap geosite berbeda-beda sehingga memerlukan konsep geohomestay yang mencerminkan potensi pada setiap geosite; 3) Terdapat 7 kawasan utama sebaran geo homestay yang akan dikelola berdasarkan criteria antara lan akes,jarak anatar geosite, pemukiman dan fasilitas penunjang geo homestay; 4) Perancangan kawasan geo homestay harus memperhatikan unsur-unsur kandungan lokal seperti rumah-rumah penduduk serta budaya dan tradisi yang ada untuk diterapkan dalam tema geo homestay.

\section{DAFTAR PUSTAKA}

Anonymous, 2017. Deskripsi Taman Nasional Tambora. Balai Taman Nasional Tambora

Burek, 2014. Geoheritage in Europe and its Conservation, W.A.P. Wimbledon, S. Meyer-Smith (Eds.) . Proceedings of the Geologists' Association. Volume 125, Issue 3, July 2014, Pages 362-363

Fandeli, C. 2002. "Perencanaan Pariwisata Alam" Penerbit Kerjasama PT Perhutani dan Fakultas Kehutanan UGM Yogyakarta.

Gray Murray. 2005. Geodiversity: developing the paradigm. Proceedings of the Geologists' AssociationVolume 119, Issues 3-4, 2008, Pages 287-298

Home Enterprise and Host : a United Kingdom Perspective. International Jurnal of Hospitality
Management 24 (533-553). Edinburgh : Elsevier.

Keli, Maksimus. 2015. Potensi Gunung Tambora.

Online. http://forest-

maxs.blogspot.co.id/2015/06/potensi-

gunung-tambora.html. Akses 23 September 2017.

Maryaeni.2005. Op.cit Hlm.75

Meliono, I. (2011). Understanding the Nusantara Thought and Local Wisdom as an Aspect of the Indonesian Education. International Journal for Historical Studies, Vol. 2(2), hal. 221-234.

Nabillah, G. (2018). Perancangan Homestay di Desa Wisata Nglinggo dengan Pendekatan Arsitektur Tropis dan Penerapan Konsep Edukatif dan Komunikatif SKRIPSI. UII JOGJAKARTA.

Singarimbun, M dan Effendi. 2010. Metode Penelitian Survai. LP3ES. Yogyakarta.

Seubsamarn, K. 2009. Tourist Motivation to Use Homestay in Thailand and Their Satisfaction Based on The Destination's

UNESCO. 2009. UHJAK/2009/PI/H/9. Ekowisata : Panduaan Dasar Pelaksanaan. Jakarta : United Nations Educational, Scientific and Culturan Organization.

Usman, H dan Akbar, P.S. 2006. Metodologi

Penelitian Sosial. Jakarta: Penerbit Bumi

Aksara.

Zulharman, 2017. Kearifan Lokal dan Strategi Pengembangan Ekowisata Tambora. Penelitian tidak dipubikasikan. 